\title{
Plotless actions with nevertheless a plot: the assemblage of a hybrid learning environment
}

\author{
Frits Simon $^{1}$ (D) Joyce Vreuls ${ }^{1}$ (D)
}

Received: 13 January 2021 / Accepted: 28 September 2021 / Published online: 29 October 2021

(C) The Author(s) 2021

\begin{abstract}
We report research into the evolvement of a hybrid learning environment where education, companies and government successfully cooperate. This hybrid learning environment-one of the latest inventions in curriculum design-is special because it was neither intended nor planned by the parties involved. With some self-astonishment, the participants in this research experienced a growing acknowledgement of their emerging educational creation, aside from the experience of and appreciation for their cooperation and the increasing turnover. With a bricolage research approach within the scope of a rhizomatic perspective on becoming, a multivocal perspective on the evolvement of the learning environment was pursued. In emphasizing the historical evolvement of the learning environment, our findings challenge the tradition of drawing board design, accompanied by an appeal for re-appreciating professional craftsmanship. In addition, some reflections regarding the research are discussed.
\end{abstract}

Keywords Rhizome $\cdot$ Bricolage $\cdot$ Assemblage $\cdot$ Hybrid learning environment . Professional craftsmanship · Post-qualitative research

It is paramount to educate students effectively and meaningfully in such a way as to foster the right professional skills. A distinction between learning in school and learning in the workplace can be made. In addition to these two traditional modes, a hybrid form of learning can be distinguished in which the strict distinctions between learning in school and in the workplace are blurred (Zitter 2010). The subject of our research is a hybrid-like learning workplace in which learners work collaboratively on real-life problems (Tynjälä et al. 2003). Through this situated learning (Lave and

The idea of plotless actions draws inspiration from a prize-winning novel by Van Essen (De goede zoon, Uitgeverij Atlas Contact, Amsterdam, 2018), in which the leading character earns a living by writing plotless thrillers.

Frits Simon

simfrits@gmail.com

1 Research Centre for Educational Innovation and CPD, Zuyd University of Applied Sciences, Heerlen, The Netherlands 
Wenger 1991), students gain knowledge through practical application of classroom theory in real-life contexts. Thus, a realistic problem serves to drive learning activities (Van Merriënboer et al. 2002).

Zitter (2010) states that designing hybrid learning environments that integrate learning in school and in the workplace is a challenging task that is far from straightforward yet, especially because two different (learning) systems of schools and workplaces with different actors, visions and rules need to be integrated (Biemans et al. 2004). Also, society, professions and a more diverse student population increasingly confront educational institutions with new demands, which warrant new approaches to providing an optimal learning experience for students during professional education (Vreuls et al. 2021).

Out of curiosity, we delved into the history of an existing successful alliance of universities, companies, an institution for intermediate vocational education and regional government. We suspected that something special had evolved since 2004. For a long time, this alliance, the Chemelot Innovation and Learning Labs (CHILL), could be typified as a loosely connected network of varying participants. In 2011 this alliance formally became a centre of expertise, a government-encouraged collaboration amongst various partners that is intended to stimulate regional economic development by offering opportunities for research to small and intermediate companies in cooperation with universities.

For two decades, successful cooperation in CHILL has evolved into what we, perhaps impertinently, label a hybrid learning environment. Our study's premise was to explore the perspective of CHILL's implementation (Van den Akker 2003). This perspective depicts how the users and participants interpret the CHILL's evolvement. CHILL appeared to be an ongoing 'result' of many interactions, events and coincidences. Hawick et al. (2017) describe such complex evolvements as wicked problems, which are associated with multiple dynamic social environments and actors, have unpredictable outcomes, are continually evolving, are influenced by many dynamic social, cultural and political factors and have no single solution path. However, for us, the evolvement of the learning environment was wicked but not a problem. Therefore, we felt compelled to rethink our methodological predispositions. ${ }^{1}$ In the paper, we try to express not only CHILL's dynamics but also the dynamics of our research, for instance, by explaining that the use of a specific tool for analysis did not bring what we hoped for.

\footnotetext{
1 At this point, locating ourselves as researchers seems appropriate. Three researchers were involved in the original research. The presentation of results always suggests a logical and straightforward process of working together and agreeing upon the many interpretations. The three of us came from different disciplines originating from strong orientations on quantitative research and traditional qualitative research and on an autoethnographic perspective on social complexity. We agreed that the conversations with the participants beckoned us to explore different angles for interpreting what had evolved. Reflecting on this, we had to explore our 'knower's mirror', our preconceptions or our beliefs (Malterud 2001). Especially when it came to labelling the narratives of the participants, we wavered. How to avoid carrying our interpretations too far? How to use theory and yet respect the participants' differences? Should or could we (not) construct a theoretical model? Something halfway between a qualitative and post-qualitative approach emerged from our discussions, enabling a balance among our theoretical, autoethnographic and qualitative ambitions.
} 
In attempting to express the dynamics, we do not provide a fixed research question. We began with the question of how an initial small lab was transformed into CHILL. However, from our early conversations with the participants, it became clear that we could not speak of a straightforward transformation, and even 'transformation' was quite suggestive. Transformation suggests too much the presence of a foundation next to the working out of well-considered blueprints. Many things that had happened and many persons from different organizations involved in the becoming of CHILL prevented us from speaking of a transformation. In hindsight, our research question can be determined as how an initial and small lab came into being and is appreciated as a hybrid learning environment. As curiosity into the becoming of CHILL-and not a problem regarding CHILL-underpins our research, we do not provide recommendations or advice.

In the beginning, we had to find our way amongst the various ways participants reconstructed their history of CHILL. They had entered and sometimes left CHILL's history at different times in various positions. Sometimes they had come with a specific assignment. Sometimes they had stayed after becoming enthusiastic. Their stories seemed rather different. We became convinced that a narrative-based bricolage approach was best suited for grasping in detail all that had happened. We chose to map the history by referring to the concepts of bricolage, rhizome and assemblage, inspired by the work of Lévi-Strauss (1962) and Deleuze and Guattari (1987). Bricolage emphasizes a practical instead of a planned way of acting. Fiddling and tinkering are correct indications of that way of acting because of their vernacular nature. Rhizome and assemblage enable us to describe the never-ending gluing and colliding (becoming) of many things (rhizomes) into temporary constellations (assemblages). Metaphorically, a rhizome can be compared with a rootstock that connects 'genetically' different elements. These concepts invite, amongst others, departure from a historical, multivocal, discursive and relational perspective (Kincheloe 2001, 2005). These concepts enabled us to understand the dynamics and unpredictability of what evolved. As such, our research findings are intended to be complementary to research that focuses on the explicit design of experiential learning labs (e.g. Cremers 2016; Zitter and Hoeve 2011). In this case, the implemented design perspective provided insights into how participants explained and appreciated what they kept on building together, without in advance being aware of what would be the outcomes of their efforts.

We present a short introduction on CHILL's context. Next, we elaborate on how our research evolved and how we mapped our results and conclusion. Some further considerations regarding curriculum design, professional craftsmanship and the quality of our research follow. In emphasizing CHILL's historical evolvement, our findings challenge the tradition of drawing board design because of CHILL's success thus far. We finish by discussing some post-qualitative aspects of our research from our rhizomatic perspective. 


\section{Context}

In 2004, the small team of managers and lecturers in a small faculty of a university of applied sciences sought ways to solve a deficit of around $€ 100,000$. They founded a small lab at the faculty, and over time, a small but growing number of companies agreed to do some of their research in this lab. This research was performed by students under their lecturers' supervision and paid for by the companies through a sort of sponsorship. An unanticipated overcapacity of students and a chance stumbling across a vacancy for lab space in a chemical plant led to the lab's move to the plant in 2007.

Leading up to 2011, pressure from the county council, a nearby research university and a big chemical company rendered the lab the cornerstone of, as it appeared, a successful application for government funding for a centre of expertise.

Approaching 2012, cooperation between the research university, some big companies, the university of applied sciences and an institution for intermediate vocational education was settled by founding a private limited company named CHILL.

CHILL now proclaims to enhance the innovative strength and competitive position of companies in the chemical sector by pairing emergent talents (bachelor's students) with the knowledge and experience of seasoned professionals. Furthermore, by organizing practical training programmes and master classes for professionals, learning is organized in communities of development (a concept like communities of practice). A community of development is defined as the realistic, project-based and result-oriented working together of students, lecturer-researchers, researchers and entrepreneurs in a professional environment, facilitating the communities to solve real problems in their own idiosyncratic ways.

\section{Research evolvement}

\section{Participants}

Our curiosity about CHILL's history was piqued by a chance encounter with one of the founding managers of the initial lab. Conversations with this founding manager enabled us to explore CHILL's situation and advance the phrasing of our research question. We adapted our research question from a focus on transformation to a narrative-based bricolage approach to be able to grasp, from a multivocal perspective, all that had happened.

Between 2016 and 2018, we spoke to 21 participants, including lecturers, students, researchers, entrepreneurs, board members, managing directors, a human resources manager, a communication officer, a professor and teachers. They had been or were still involved in CHILL. Having started with a founder, the other 20 participants were selected by asking each participant whom to approach next as being important in CHILL's history. After two years, the saturation of names restricted the number of participants. 


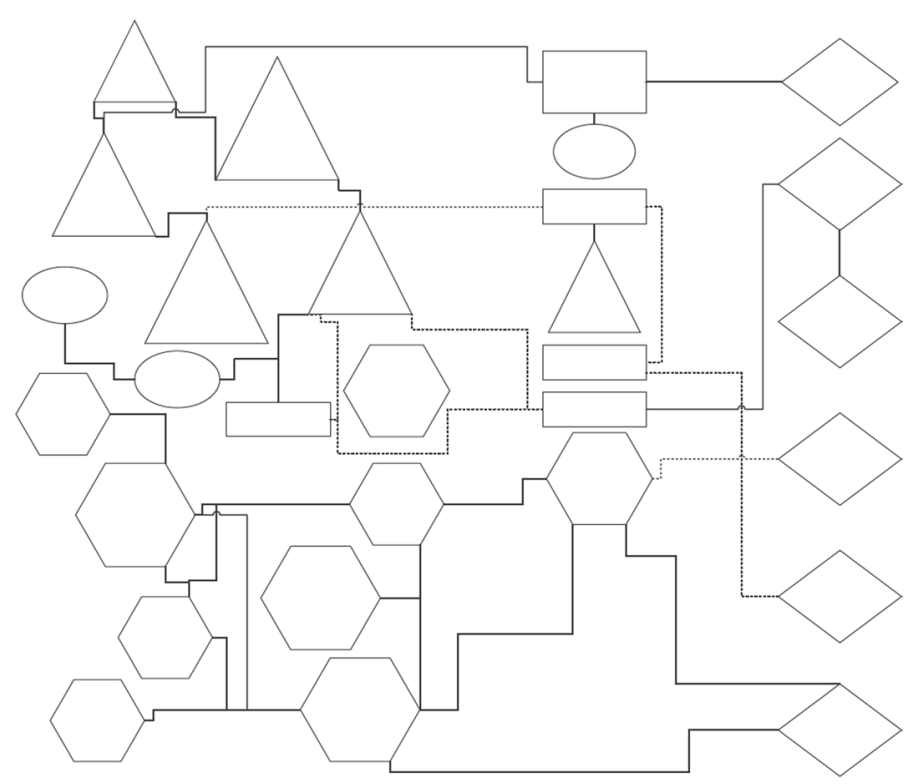

Fig. 1 An exemplary rhizome of a conversation

\section{Procedure}

To acknowledge multivocality and precluding our predispositions as much as possible, a simple leading question was used to start the conversations, namely how the participant looked back at the coming into being of CHILL.

Every conversation was transcribed and reported by us as researchers. Because everything would be made public, in the report the transcripts were translated into a readable narrative. During our research, we embraced a rhizomatic approach (Deleuze and Guattari 1987) for mapping the conversations. The conversations 'invited' us to do so because they reflected a complex and ambiguous history of becoming. Concepts like bricolage, assemblage and becoming helped to emphasize the dynamics that evolved and how different things had clotted together and led to unexpected and unforeseen events. Finally, we drew a rhizome based on every single report (Fig. 1 is an example).

To acknowledge CHILL's heterogeneous and complex history, we opted for dialogical, democratic, process, result and catalytic validity as poststructuralist standards to ensure the quality of the research (Anderson and Herr 1999). The participants were informed about every intended step or action and offered the opportunity to respond. They were also asked to approve the rhizomatic understanding of the conversations and the draft of our overall research report. We avoided forcing our demands as researchers. In the end, with consent, 16 conversations were used to map the results. We could not use five reports because those participants failed to comment on their reports. For use and publication, we anonymized the reports and, when requested, rephrased the less tactful and vernacular pronouncements in the 
reports. We omitted details in the narratives to preclude identifiability. However, we still used these details to underpin our findings. Unavoidably, participants are still recognizable to colleagues and stakeholders. This is inevitably connected to our wish to acknowledge multivocality, heterogeneity and complexity. Moreover, to foster multivocality, we published, with everyone's consent, all the final reports and rhizomes on a public website. ${ }^{2}$ Consequently, all participants could check our mapping.

\section{Analysis}

We aimed to do justice to everyone's perspectives. After closely reading the reports, we first labelled the participants' statements on a rather general level. We differentiated statements regarding educational, relational/power and logistic matters from statements that indicated contextual societal developments, changes in participants' formal positions, former experience and developments within participants' own organizations. Furthermore, we labelled statements contemplative when participants expressed concerns regarding the future. Labelling implies that we identified the subject of a statement, but we had no intention to pursue causal relations or a theoretical framework based on the statements. Given our rhizomatic orientation, we were curious about what had come together; we were not searching for explanatory variables.

Next, to respect the kinds of statements and reasoning of every participant, we drew a rhizome for every conversation (see Fig. 1). Somewhat inspired by Deleuze and Guattari (1987, p. 1), we assumed that this helped by visualizing each participant's specific logic. The labelling had to expose the similarities, and all rhizomes taken together would allow us to display the differences in wording and reasoning. The statements indicated differences in the sequences of interactions and events as well as their mutual relatedness and assigned significance.

In the example in Fig. 1, some labels are not present, exemplifying the differences among participants. ${ }^{3}$ For the different kinds of participant statements, we used different symbols in the rhizome. An unbroken line indicates the displayed reasoning; it shows which kind of statements in which order and through which connections were made. A dotted line indicates enduring reflections on subjects. Table 1 displays the symbols used.

By drawing rhizomes and taking them together, we aimed to design an overall map of all the statements to visualize the complexity of CHILL's becoming. However, the combined reality of all the participants appeared to be too multifarious. Therefore, an overall map appeared to be impossible, regretfully the specific

\footnotetext{
${ }^{2}$ https://figshare.com/articles/dataset/_worden_van_en_CHILL_en_en_-_een_momentopname_van_ een_hybride_leeromgeving/7893062. Because on this website we use the real name of the alliance, we use it also throughout this paper. In publishing the narratives on this website, we enable Dutch-speaking readers to suggest a different understanding and allow more and different explorations in the future.

3 To give the reader an idea about the rhizomes, we adapted a rhizome for this article. Originally, we used different colours instead of geometrical forms to indicate the kinds of statements and draw the lines. Due to the restrictions of this journal, we left out the statements. The size of the different forms in the displayed rhizome has little meaning. The size depended on the length of the statement.
} 
Table 1 Symbols used to draw the participants' rhizomes

\begin{tabular}{l}
\hline Statements concerning \\
Education \\
Relations/power \\
Logistics \\
Societal developments \\
Formal position \\
Former experience \\
Organizational developments \\
Contemplations \\
Reasoning \\
Enduring reflections
\end{tabular}

rhizomes acquired only a restricted visualizing purpose. Our overall attempt is on the public website.

\section{Mapping the findings}

We illustrated the complexity of CHILL's becoming and appreciation according to the participants. Every participant appeared particularly aware of the many ongoing efforts that were made and that must be accomplished in an alliance such as CHILL. In cooperating, the participants experienced different institutional and personal policies, conflicts of interest, disappointments, uncertainties, interdependencies, some luck and sometimes seemingly arbitrary interventions. We do not go into many details about the specifics of cooperation, as this behaviour is business as usual and rather all too human. However, of special interest is that none of the participants mentioned something like 'lessons learned', as if from now on they would know how to cooperate. This notion emphasizes that the participants experienced the benefits of their efforts. This notion underlines our first finding that CHILL is a temporary plot of plotless actions.

\section{A temporary plot of plotless actions}

CHILL evolved from various non-simultaneous events, many actions, different policies, some fortune and different interventions in a coming together of unlike and non-coincidental happenings. As the participants indicated, the societal context was undoubtedly favourable because governmental policy aimed at getting more students interested in technological sciences. However, the coming together of the coincidental presence of a small lab in the chemical plant, an unpredicted overcapacity 
of first-year students and the exerted managerial and political pressure to apply for funding for a centre of expertise was opportune. What if the lab had not been there as a cornerstone for the application?

The overcapacity of students has its own history and significance. In Dutch higher education, first-year students who end their studies before the first of February of their first-year can re-enter the same studies without any threshold and with no debts next year. A large group of first-year students with apparently disappointing results was tipped off by a lecturer to end their studies in time so that they would be able to return next year without any delay. Many students from this group re-entered and caused the overcapacity. For mixed logistic and power-driven reasons-varying from being required to offer an educational environment to a sort of castigation-this group was scheduled at the chemical plant. Because of the plant's different resources and possibilities, the lecturers had to adapt their way of teaching. Surprisingly, this student group became one of the groups with the best grades ever. Unintentionally, this group unlocked insights that conclusively contributed to the development of the communities of development. What if the lecturer had not tipped them off? The lecturer's action was not applauded.

The participants' narratives offered more examples of coincidences, although this suggests that serendipity explains everything. Our notion is that many people acted with the best of intentions. Everyone involved tried to solve their problems and pursue their ambitions, but never intended to establish CHILL as it was at the time of our research. It is interesting that a dynamic, surprising and sometimes uncomfortable working environment became established and appreciated.

\section{No CHILL without bricoleurs}

Contrary to the conclusion that CHILL emerged instead of being planned, the participants identified the presence of a small group of epoch makers or bricoleurs. Although several managers, professors, entrepreneurs, students, lecturers, board members, coaches and policymakers were involved through the years, somehow these bricoleurs appear to be important in CHILL's becoming. Through continued vigilance, discussion and monitoring, this group-whose membership varied throughout time and remains somewhat mystical-kept its finger on the pulse of what was/is happening and responded/responds, for instance, as a go-between for the many discussions about educational demands, contractual liabilities, professional identity, cooperation and accountability or by exceeding boundaries by developing an idea about introducing sponsorship to avoid VAT obligations.

Otherwise, these bricoleurs acted as the regime's guardians when, out of the blue, the quartermaster for the alliance from one university was replaced by the managing director of a commercial partner. On a board level, this had been arranged but was never clarified, even for the quartermaster himself, who was sure he had learned to walk on eggshells. Some experienced this as power play and feared commercialization. The bricoleurs cared deeply about upholding developmental dynamics and preventing organizational ossification. They did not strive for this role, nor were they formally appointed or made responsible. 


\section{Successful curriculum design without a blueprint}

The participants described a type of curriculum design characterized by the concurrence of many relations, logistic matters and organizational developments, to mention just a few things. Some companies reorganized and made staff redundant, who therefore were replaced temporarily at CHILL. Old furniture was saved from the rubbish bin; otherwise, there would have been no bureaus to work on at the lab. Public transport for the students to the chemical plant was only realized after some years. The inevitable and recurring hustle for money for years caused recurring uncertainty and a stimulus to survive. Some members of staff were disappointed with earlier educational reforms, so could it be worse anymore? The beneficial presence of members of staff with PhD's, who had experience of funding and research, is explained because several had accepted low pay grades at the university of applied sciences due to a lack of career opportunities at their former research universities.

A distinct finding is that one of the lab's founding fathers had an unexpected opportunity to become dean of a teacher's college for primary education, and he experienced what a pedagogical climate could mean for students and employees. This college was about to introduce communities of practice as a way of working with primary schools. Returning to CHILL some years later he had much experience and many ideas about cooperation between education and companies. His unintended side tour was converted into an inspiring pedagogical contribution.

Obviously, one cannot speak of systematic curriculum design (for instance, O'Neill 2015), although CHILL can be seen as quite a radical change to an existing rather traditional educational praxis. Although cooperation and coordination did not always advance smoothly, CHILL satisfactorily evolved out of various non-simultaneous events.

Elaborating on the participants' satisfaction with and appreciation of CHILL, we found that participants were surprised by their own success and experienced some changes but also worried about the future.

\section{Too good to be true? Astonishment and disbelief}

CHILL's experienced but unplanned effectiveness may explain the participants' simultaneous disbelief and astonishment. Participants' statements, such as 'would never have guessed', 'realized that time must be on our side' and 'hats off for this accomplishment', illustrate their astonishment and a certain disbelief. They cherished the cooperation that emerged, the increase in turnover and growing acknowledgement by educational institutions. Nevertheless, participants mentioned the lack of involvement of some partners, seemingly arbitrary changes in management, cultural differences between educational and business organizations, resistance and a lack of enthusiasm from some fellow lecturers and middle managers and the uncertainty of their financial backing. They wondered what would have happened if, for instance, the county council had withdrawn its support or the rental price for the labs in the chemical plant had become too expensive for the educational institutions. 
The participants appeared aware of their strong interdependency and the coincidence and vulnerability of their undertakings. Time and again, things had turned out all right. Emergence, instead of planning, may be a proper expression of the participants' experiences.

\section{Becoming a man! Educational impact and job satisfaction}

An archaic Dutch saying originating from the military draft is that, away from the mother's bosom, a boy will become a man. However, one participant used this expression to indicate that students who enter CHILL gain self-awareness and learn to understand what suits them. Students' personal growth is served by the realistic education offered through CHILL's projects. Many participants shared this experience.

During the projects and due to the obligation to produce results, a less formal and more fraternal relationship evolved between the students and the lecturers. Being on a first-name basis had to be learned by both parties. Everyone had to get used to this kind of relationship, perhaps lecturers in particular, because they had to leave behind their traditional positions as omniscient narrators and assessors.

For all involved, project-based realistic education appears less noncommittal. It produces a work ethic through which problem-solving competences are promoted, and teamwork and cooperation apparently obligate everyone involved. Particularly for employees, job satisfaction increased.

\section{Double-edged concerns about the future}

The adage, 'If men define situations as real, they are real in their consequences' (Thomas and Thomas 1928), is appropriate for considering the participants' contemplations and concerns about the future. They had many worries, including the necessary turnover to survive, the required lasting involvement of different partners, the consequences if CHILL keeps on expanding, a wished-for marketing strategy, the influence of commercialization on working relations and the position of students if CHILL becomes increasingly business-like.

These concerns point to diverse, if not conflicting, tensions within CHILL. For instance, a longed-for stable turnover may be at odds with concerns about the influence of commercialization on working relations or the students' position.

Given the way CHILL evolved until now, these concerns can be labelled double-edged. First, the concerns are real and must be taken seriously. Denying their existence would mean denying everyday reality as experienced by the participants. Second, the way the participants articulated their concerns is not non-committal. In some way, these articulations will be real in their consequences, although which solutions will emerge is hard to predict. Yet, they will be there because, after all, the becoming of CHILL is a history full of solutions-solutions despite and/or thanks to double-edged concerns of all sorts. 


\section{Commentary}

\section{CHILL as a self-organizing plot of plotless actions}

We have presented CHILL as a concurrence of events and interactions. This concurrence is explained as bricolage, which was coined by the French anthropologist Lévi-Strauss (1962). It points to a practical way of acting in view of the circumstances. This acting, compared to our Western rational and systematic way of planning, appears wild, opportunistic and local. However, it is very effective and in no way inferior to our predominantly rational preferences. That is why we speak of plotless actions with nevertheless a plot. We have mapped CHILL as a rhizome and an assemblage it is becoming. It is ever growing, a network of heterogeneous elements that derives its purpose from what it is.

CHILL can be explained as an inventive collaboration that emerged through the cooperation of many people within businesses and educational and scientific institutions. From a complexity perspective, ${ }^{4}$ emergence is a way of understanding how the flow of many local interactions produces patterns (Stacey 2010). Through this, CHILL can be understood as a self-organizing pattern of cooperating people. It also becomes clear that organizational life can be described as a bunch of processesread: persons-in which, for instance, perseverance, creativity, policy and coincidence play a bigger part than the magico-mythical prescriptions of plan-do-checkact cycles (Mowles 2011).

\section{The risk of bestowing the term 'hybrid learning environment' on CHILL}

By typifying CHILL as a hybrid learning environment, it became possible to enter into two discussions within the educational science field. As no participant explained the existence of CHILL as such, we will explain why this educational attribute is bestowed upon CHILL. This attribute emphasizes appreciation for the results but also contains some risk.

Hybrid learning environments—although differently labelled—have become a topic of great interest (Anderson and McCune 2013; Cremers 2016; Huisman et al. 2010; Thunnissen and Custers 2018; Tuunainen 2005; Zitter 2010; Zitter and Hoeve 2011). Hybrid learning environments are ideally defined as an educational praxis in which education is combined with acquiring business experience and is preferably implemented in a real business environment. As such, CHILL is exemplary.

We foresee some risks in this typology. With growing interest, overall design principles and guidelines for hybrid learning environments started to be outlined (e.g. Cremers 2016; Zitter and Hoeve 2011) that by nature address education as something to prefabricate (Wallin 2011). Conversely, CHILL's emergence exemplifies that valued educational innovations can be imagined as ongoing and unpredictable processes of interaction, cooperation and adjustment. In CHILL's case, overall

\footnotetext{
${ }^{4}$ Deleuze may be seen as a philosopher of complexity avant la lettre (De Landa 1998).
} 
guidelines or design principles were apparently obsolete. However, in future, overall design principles and guidelines may be reified by quality assurance. Ossification may await CHILL, a risk that is getting closer due to our typifying of CHILL as a hybrid learning environment. Due to this, it may risk being measured against unfamiliar criteria. For CHILL, this may lead to what Deleuze and Guattari (1987) call machine-like assemblages.

\section{Re-appreciation of professional craftsmanship}

Our typifying of CHILL has one advantage at least. Whereas the responsibility for education has become a matter of scientific management (Halffman and Radder 2015; Pavlopoulos 2014; Stoller 2015) and is mainly reduced to accountability (Van den Brink 2020), CHILL offers an auspicious perspective on professional craftsmanship. Through many people's ongoing efforts, a valued, not unworldly, educational practice has emerged. Moreover, CHILL is not a design still to be realized, like many other designs, but it works. CHILL is an emergent practice. Zijlstra and Van den Bogaard (2018) describe emergent practices as self-organizing educational practices that progress by experimenting, reflecting and adjusting. CHILL can be seen as incarnate proof of trusting professionals and their craftsmanship-professionals who prefer to build together instead of responding to top-down directions (Homan 2013).

\section{Quality of research}

We opted for poststructuralist standards (Anderson and Herr 1999), which are valued as classical (Heikkinen et al. 2016), to ensure the quality of the research, acknowledging the multivocality, heterogeneity and complexity of the history. Did we succeed?

Anderson and Herr (1999) distinguish dialogical, democratic, process, result and catalytic validity. Democratic validity demands that all stakeholders have their say about how the themes will be researched. Dialogical validity demands the presence of critical friends. Process validity requires multivocal and reflective problematizing. Result validity demands that the results be experienced as a realistic outcome for the problems experienced. Catalytic validity assumes that the results will inspire change.

Dialogical validity was well-preserved because three researchers ${ }^{5}$ were involved in the project. Moreover, the research-proposal, the continuation and progress next to the results were discussed in a research-group.

Discussing result and catalytic validity has little use. Result and catalytic validity are irrelevant because curiosity, not a problem to be solved, prompted this research. The outcome of this research may inspire participants and other readers to continue, but we did not aim to provide recommendations or advice. Nonetheless, this

\footnotetext{
5 To avoid misunderstanding: only two of the three researchers had the opportunity to write this article.
} 
research's outcome problematizes standard approaches to curriculum design, so it may have an impact beyond result and catalytic validity. It may energize all sorts of professionals to realize that their actions are far more real than drawing board designs. Therefore, democratic and process validity need to be considered even more, given our multivocal intentions.

The alteration - the becoming - of our research question points at multivocality. Starting from the idea of a lab's transformation, we learned from the participants to envision what happened as a way of becoming. In practice, we asked how the participants looked back at CHILL's coming into being. Finally, we answered the question of how CHILL had become and was appreciated.

The participants selected each other. The open style of the conversations with the participants, the fact that we informed and invited participants to respond to every step we intended to take, including our intention to use a rhizomatic perspective, and the requested approval of the transcripts, reports, rhizomes and final report reflected how we involved the participants. The participants always provided their approval and sometimes responded enthusiastically. Their consent for publishing the reports and rhizomes on a public website is a mark of democratic and process validity.

Democratic and process validity are easier to demand than to realize. Both require participants' effort and time. We believe that we organized our research so that the participants had a strong influence-with one quite important exception: the framing of the conversations in terms of a rhizomatic approach. Although we felt that the conversations invited us to use this approach, it is not an approach that is part of everyday conversations. That begs the question of whether we-not unlike other researchers-considerably reduced the participants' contributions.

\section{Discussion}

A hybrid learning environment was neither foreseen nor planned. We used a rhizomatic approach to map of what emerged. We recognize the dangers of bestowing the qualification of hybrid learning environment upon ongoing developments. It is interesting to question what the consequences are of bestowing concepts upon an evolving practice.

\section{Bricolage in perspective}

Our research connects to many themes regarding what is assumed and what needs to be reformed in higher education. Higher education is depicted as in need of reform, whether needing another type of professional (e.g. Brew et al. 2018; Fisher and Atkinson-Grosjean 2002; Wallin et al. 2019) or hybrid practices (e.g. Tuunainen 2005). We observe that, based on Louvel (2013), bricolage has become an oft-mentioned concept to indicate how reform is taken on in higher education (e.g. Kolmos et al. 2016; Leišytė and Sigl 2018; Padilla-Meléndez et al. 2020). These authors mistakenly represent bricolage as a deliberately chosen change strategy, although bricolage is not a deliberate strategy but a practical way of constantly acting in response 
to circumstances. Bricolage should not be represented as a deliberate change strategy. Will perseverance, creativity, policy and coincidence be lost in emergent practice if bricolage is bestowed as a deliberate change strategy?

\section{Professional emancipation}

We recognized the craftsmanship needed for such a long-lasting and ongoing endeavour and articulated this using a rhizomatic approach. This approach is not unfamiliar in education. A critical reflection on the way education is dominated by Western developmental psychology (Sellers 2013, 2015) or on how teachers are excluded from discussions about their positions (Atkinson and Rosiek 2009) are exemplary. In general, rhizomatic approaches plead for open and more experimental learning practices (e.g. Higher Education Academy 2018). Our research underlines how successful education emerged from many people's actions.

Connected to this, we wonder whether CHILL's evolvement appeals to a reappreciation of professional craftsmanship. It points to Biesta's (2014) to the imagination appealing educational theory. Based on the French educationalist Rancière, Biesta opts for a performative perspective on emancipation, which is emphasized as what people really do and/or achieve through their own actions, not by fulfilling the ambitions of some guru or fashionable policies.

The achievements of the professionals involved in CHILL epitomize this performative perspective on emancipation. As researchers, we only helped to expose what they did. Only later did we learn that our research inadvertently encouraged the professionals involved in CHILL to stick to their courses of action. It is interesting to ask how research may enable professionals to shape their work according to their own aspirations.

\section{Post-qualitative perspective on research}

The conversations with the participants obtained a different significance compared with mainstream qualitative research. Instead of theorizing derived from the conversations, rhizomatic theorizing was bestowed upon the conversations. We did not intend to mirror the participants' assumed authentic and shared realities. We articulated CHILL as a zigzag of creativity, unpredictability and out-of-the-box actions. CHILL typifies organizational life as a playground, albeit more political than is suggested by the word playground. Ultimately, we wonder if our bricolage/rhizomatic approach indeed helped to multiply knowledge instead of simplifying it (Jackson and Mazzei 2012).

Connected to this post-qualitative perspective, we wonder if we should have paid more attention to the fact that CHILL also evolved through socio-material elements, such as labs, a chemical plant, and a lack of lab space at the university, not to mention specific geographical locations (not) within easy reach and the (lack of) equipment needed. Interactions and cooperation were enacted in tangible material circumstances, whose linkages can also be assembled, reassembled and transformed (Edwards et al. 2011). We are aware that socio-material elements co-defined what 
was happening. However, regarding the specific nature and impact of this co-defining, we are still at a loss for an answer.

Further research into the impact of socio-material elements seems obvious. What is the impact on staff and students when education is transferred to a chemical plant and must be organized amidst exhaust pipes and cooling towers? Will students experience growing self-awareness or become part of a totalizing machine-like assemblage (see Pedersen 2013)? Research into the impact of these elements is needed because higher education is becoming more decoupled from its traditional geographical concentration in one specific building. IT or maybe hybrid learning environments are leading the way.

Acknowledgements We thank Miriam Stuijts for her cooperation during our research and Marcel van der Klink for his critical comments on earlier versions of this paper.

Data availability Our manuscript has associated data in a repository (see footnote 3).

\section{Declarations}

Conflict of interest The authors have no conflicts of interest to declare that are relevant to this article's content. All authors certify that they have no affiliations with or involvement in any organization or entity with any financial or non-financial interest in the subject matter or materials discussed in this manuscript. The authors have no financial or proprietary interests in any material discussed in this article.

Informed consent The authors obtained informed consent from the participants to use their information and publish their narratives and rhizomes on a public website.

Open Access This article is licensed under a Creative Commons Attribution 4.0 International License, which permits use, sharing, adaptation, distribution and reproduction in any medium or format, as long as you give appropriate credit to the original author(s) and the source, provide a link to the Creative Commons licence, and indicate if changes were made. The images or other third party material in this article are included in the article's Creative Commons licence, unless indicated otherwise in a credit line to the material. If material is not included in the article's Creative Commons licence and your intended use is not permitted by statutory regulation or exceeds the permitted use, you will need to obtain permission directly from the copyright holder. To view a copy of this licence, visit http://creativecommons.org/licen ses/by/4.0/.

\section{References}

Anderson GL, Herr K (1999) The new paradigm wars: is there room for rigorous practitioner knowledge in schools and universities? Educ Res 28(5):12-21

Anderson C, McCune V (2013) Fostering meaning: fostering community. High Educ 66(3):283-296

Atkinson BM, Rosiek J (2009) Researching and representing teacher voice(s): a reader response approach. In: Jackson AY, Mazzei LA (eds) Voice in qualitative inquiry. Challenging conventional, interpretive, and critical conceptions in qualitative research. Routledge, New York, pp 175-196

Biemans H, Nieuwenhuis L, Poell R, Mulder M, Wesselink R (2004) Competence-based VET in the Netherlands: background and pitfalls. J Profess Educ Train 56(4):523-538

Biesta G (2014) The beautiful risk of education. Paradigm Publishers, Boulder

Brew A, Boud D, Lucas L, Crawford K (2018) Academic artisans in the research industry. High Educ 76(1):115-127 
Cremers PHM (2016) Designing hybrid learning configurations at the interface between school and workplace. Wageningen University, Wageningen

De Landa M (1998) Deleuze and the open-ended becoming of the world. Chaos/control Complexity Conference. University of Bielefeld, Germany.

Deleuze G, Guattari F (1987) A thousand plateaus. Capitalism and schizophrenia, 2016th edn. Bloomsbury, London

Edwards R, Fenwick T, Sawchuk P (2011) Emerging approaches to educational research: Tracing the socio-material. Routledge, Milton Park

Fisher D, Atkinson-Grosjean J (2002) Brokers on the boundary: academy-industry liaison in Canadian universities. High Educ 44(3-4):449-467

Halffman W, Radder H (2015) The academic manifesto: from an occupied to a public university. Minerva 53(2):165-187

Hawick L, Cleland J, Kitto S (2017) Getting off the carousel: exploring the wicked problem of curriculum reform. Perspect Med Educ 6:337-343. https://doi.org/10.1007/s40037-017-0371-z

Heikkinen HLT, Jong FPCM, Vanderlinde R (2016) What is (good) practioner research? Vocat Learn 9:1-19

Higher Education Academy (2018) Rhizomatic learning. https://www.heacademy.ac.uk/knowledge-hub/ rhizomatic-learning

Homan T (2013) Het et-cetera principe. Een nieuw perspectief op organisatieontwikkeling. Academic Service.

Huisman J, de Bruijn E, Baartman L, Aalsma E (2010) Leren in hybride leeromgevingen in het beroepsonderwijs. Praktijkverkenning, theoretische verdieping. ECBO.

Jackson AY, Mazzei LA (2012) Thinking with theory in qualitative research: viewing data across multiple perspectives. Routledge, Milton Park

Kincheloe JL (2001) Describing the bricolage: conceptualizing a new rigor in qualitative research. Qual Inq 7(6):679-692

Kincheloe JL (2005) On to the next level: continuing the conceptualization of the bricolage. Qual Inq 11(3):323-350

Kolmos A, Hadgraft RG, Holgaard JE (2016) Response strategies for curriculum change in engineering. Int J Technol Des Educ 26(3):391-411

Lave J, Wenger E (1991) Situated learning: legitimate peripheral participation. Cambridge University Press, Cambridge

Leišyte L, Sigl L (2018) Academic institutional entrepreneurs in Germany: navigating and shaping multilevel research commercialization governance. Triple Helix 5(1):1-23

Lévi-Strauss C (1962) The savage mind, 1968th edn. University of Chicago Press, Chicago

Louvel S (2013) Understanding change in higher education as bricolage: how academics engage in curriculum change. High Educ 66(6):669-691

Malterud K (2001) Qualitative research: standards, challenges, and guidelines. Lancet 358(9280):483-488

Mowles C (2011) Rethinking management. Gower Publishing, Radical insights from the complexity sciences

O'Neill G (2015) Curriculum design in higher education: theory to practice. UCD Teaching and Learning. http://hdl.handle.net/10197/7137

Padilla-Meléndez A, Aguila-Obra D, Rosa A, Lockett N, Fuster E (2020) Entrepreneurial universities and sustainable development. The network bricolage process of academic entrepreneurs. Sustainability 12(4): 1403

Pavlopoulos D (2014) Arbeidsrelaties aan een universiteit in de greep van new public management. In Becker F, Hurenkamp M, Dekker R (eds) De gelukkige onderneming. Jaarboek voor de sociaaldemocratie (pp. 133-150). Wiardi Beckman Stichting, Uitgeverij Van Gennep.

Pedersen H (2013) Follow the Judas sheep: materializing post-qualitative methodology in zooethonographic space. Int J Qual Stud Educ 26(6):717-731

Sellers M (2013) Young children becoming curriculum: Deleuze. Routledge, Te Whãriki and curricular understandings

Sellers M (2015) ... working with (a) rhizoanalysis... and... working (with) a rhizoanalysis.... Complicity 12(1):6-31

Stacey R (2010) Complexity and organizational reality. Uncertainty and the need to rethink management after the collapse of investment capitalism. Routledge, Milton Park

Stoller A (2015) Taylorism and the logic of learning outcomes. J Curric Stud 47(3):317-333. https://doi. org/10.1080/00220272.2015.1018328 
Thomas WI, Thomas DS (1928) The child in America. Knopf, Behavior problems and programs Thunnissen M, Custers M (2018) Social labs: innovatie in het hbo. Onderwijsinnovatie 1:13-15

Tuunainen J (2005) Hybrid practices? Contributions to the debate on the mutation of science and university. High Educ 50(2):275-298

Tynjälä P, Välimaa J, Sarja A (2003) Pedagogical perspectives on the relationships between higher education and working life. High Educ 46(2):147-166

Van den Akker J (2003) Curriculum perspectives: an introduction. In: Van den Akker J, Kuiper W, Hameyer U (eds) Curriculum landscape and trends. Kluwer Academic Publishers, pp 1-10

Van den Brink G (2020) Ruw ontwaken uit de neoliberale droom en de eigenheid van het Europese continent. Prometheus.

Van Essen R (2018) De goede zoon. Uitgeverij Atlas Contact, Amsterdam.

Van Merriënboer JJG, Clark RE, de Croock MBM (2002) Blueprints for complex learning: the 4C/IDmodel. Educ Tech Res Dev 50(2):39-61

Vreuls J, Stoyanov S, Koeslag-Kreunen M, Van der Klink M, Nieuwenhuis L, Boshuizen H (2021) Responsive curriculum development: which (f)actors support breaking through the institutional concrete? Online conference Educational Research. University of Applied Sciences Utrecht, ORD

Wallin JJ (2011) What is? Curriculum theorizing: for a people yet to come. Stud Philos Educ 30(3):285-301

Wallin A, Nokelainen P, Mikkonen S (2019) How experienced professionals develop their expertise in work-based higher education: a literature review. High Educ 77(2):359-378

Zijlstra W, Van den Bogaard M (2018) Studiesucces en de noodzaak van nieuw denken en handelen. In Glastra F, Middelkoop DV (eds) Studiesucces in het hoger onderwjs. Van rendement naar maatschappelijke relevantie. Eburon, pp 167-195.

Zitter I (2010) Designing for learning. Studying learning environments in higher professional education from a design perspective [PhD dissertation]. University of Utrecht.

Zitter I, Hoeve A (2011) Ontwikkelmodel voor hybride leeromgevingen in het beroepsonderwijs. ECBO. 